\title{
Nasal and nasoethmoidal-orbital fractures: A continuum of injury
}

\author{
Mohammed M Elahi MD MSc FRCSC ${ }^{1}$, Bernard L Markowitz MD FACS ${ }^{1,2}$ \\ ${ }^{1}$ Division of Plastic \& Reconstructive Surgery, UCLA School of Medicine, Los Angeles, and ${ }^{2}$ Division of \\ Plastic \& Reconstructive Surgery, UCLA - Olive View Medical Center, Sylmar, California
}

\section{Elahi, BL Markowitz. Nasal and nasoethmoidal-orbital fractures: A continuum of injury. Can J Plast Surg 2000;8(2):73-77.}

\begin{abstract}
The unilateral nasoethmoid orbital (NOE) fracture is frequently misdiagnosed. This fracture is independent of the clinically obvious NOE fracture and has alternately been referred to as complex nasal, minimally displaced, occult or greenstick NOE fracture. Failure to identify and treat these injuries at initial presentation results in undesirable aesthetic and functional consequences that are difficult to repair secondarily. Three patients who presented with nasal fractures complicated by minimally displaced fractures of the medial orbital wall were reviewed retrospectively. These injuries were successfully diagnosed and treated after their examining physicians failed to appreciate the injury on the initial evaluation. Complex nasal injuries with fracture extensions to the NOE are often missed by the examining physician. These injuries should benefit from a high index of suspicion and be evaluated with axial and coronal computed tomographic imaging. Acute treatment with appropriate exposure, open reduction, internal fixation and bone grafting is most compatible with a successful outcome.
\end{abstract}

Key Words: Complex nasal fracture; Computed tomography; Minimally displaced; Nasoethmoidal-orbital fracture; Occult fracture; Unilateral

\section{Les fractures nasales et nasoethmoïdales-orbitales : Une lésion peut en cacher une autre}

RÉSUMÉ : La fracture unilatérale au niveau nasoethmoïde orbital fait souvent l'objet d'un diagnostic erroné. Cette fracture est différente de la fracture du même type cliniquement manifeste et a déjà été appelée fracture nasale complexe, fracture avec déplacement minimal, fracture occulte ou fracture en bois vert. Si ce type de blessure n'est ni identifié, ni traité adéquatement dès le début, on risque d'assister à des complications d'ordre esthétique et fonctionnel qui sont difficiles à corriger par la suite. On a étudié rétrospectivement le cas de trois patients ayant subi des fractures du nez compliquées de fractures avec déplacements minimaux de la paroi orbitale médiane. Ces lésions ont été adéquatement identifiées et traitées après qu'un examen initial ait échoué à le faire. Les lésions nasales complexes avec extension de la fracture jusqu'au niveau nasoethmoïde orbital passent souvent inaperçues lorsque le médecin les examine. Ces blessures devraient faire l'objet d'un fort indice de suspicion et être évaluées au moyen de techniques d'imagerie axiales et coronales. Le traitement immédiat, qui passe par une exposition appropriée, une réduction ouverte, une fixation interne et une greffe osseuse, a de meilleures chances de donner de bons résultats.

$\mathrm{T}$ he nasal bones are the most commonly fractured segment of the facial skeleton; over $50 \%$ of fractures from blunt maxillofacial trauma are sustained in this area $(1,2)$. The prominent position and the relatively poor resistance offered by the osseocartilaginous framework predispose the

\footnotetext{
Correspondence and reprints: Dr Bernard L Markowitz, 200 Medical UCLA Plaza, Suite 465, Box 956960, Los Angeles, California 90095-6960, USA. Telephone 310-206-3759, fax 310-206-7579, e-mail bmarkowitz@mednet.ucla.edu
}

nasal pyramid and underlying septum to varying degrees of comminution and displacement.

The injury that results is related to the mechanism of injury and patient variables, including age and tissue resilience. These factors are in dynamic interplay with the direction, magnitude and concentration of force applied over the facial skeleton (3-5). These latter parameters primarily dictate not only the extent of local nasal injury, but also the involvement of the ethmoidal-orbital complex and adjacent bony structures in the ultimate fracture pattern. 


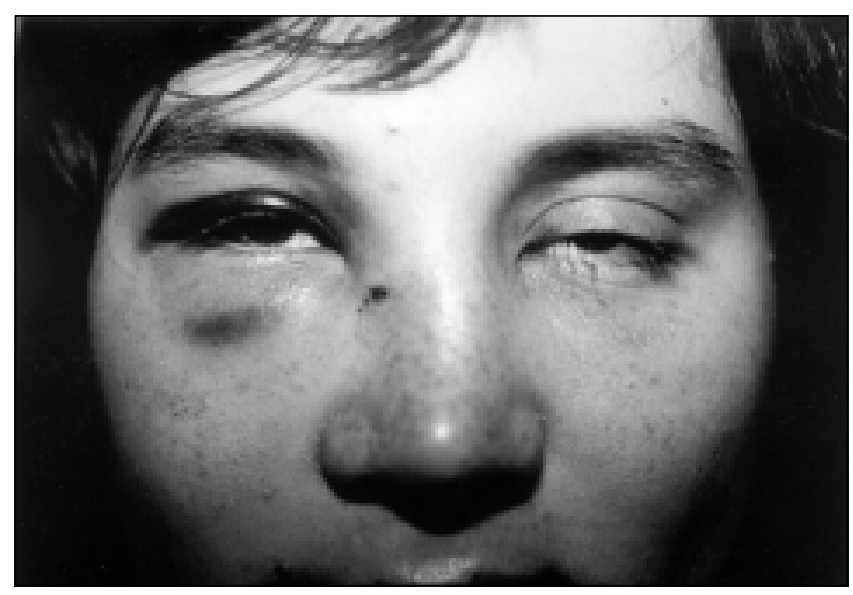

Figure 1) Lateral nasal impact with a softball

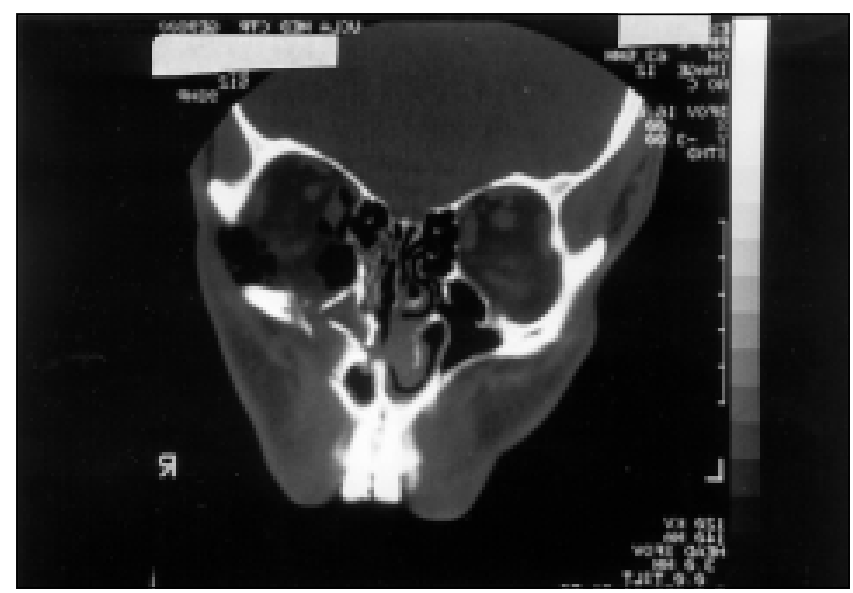

Figure 2) Coronal computed tomographic image depicting medial orbital wall, infraorbital rim and orbital floor fractures

Nasal fractures in and of themselves are generally easy to diagnose and treat $(6,7)$. The vast majority of simple injuries are successfully treated by either closed or open reduction with high degrees of efficacy and patient satisfaction $(6,8)$. Nevertheless, a high index of suspicion is needed to recognize the more elusive type of nasal fractures complicated by occult bony fractures within the nasoethmoid orbital (NOE) complex and beyond. These fractures are a subset of the clinically obvious NOE fracture and have alternately been referred to as complex nasal, minimally displaced, occult or greenstick NOE fractures (9-11). Before it can be concluded that a fracture is localized to the nasal skeleton alone, the relative contributions of posterior and lateral impact forces must be characterized by careful physical examination and ancillary studies as required. All too often, on cursory examination, the physician fails to appreciate critical NOE and adjacent bony fractures that go unrecognized at the time of diagnosis and reduction. This sequence of events condemns the patient with complicated nasal fracture to the undesirable sequelae of untreated NOE fractures and the inherent complexities of revision surgery $(13,14)$.

The burden of proof is on the treating surgeon to rule out

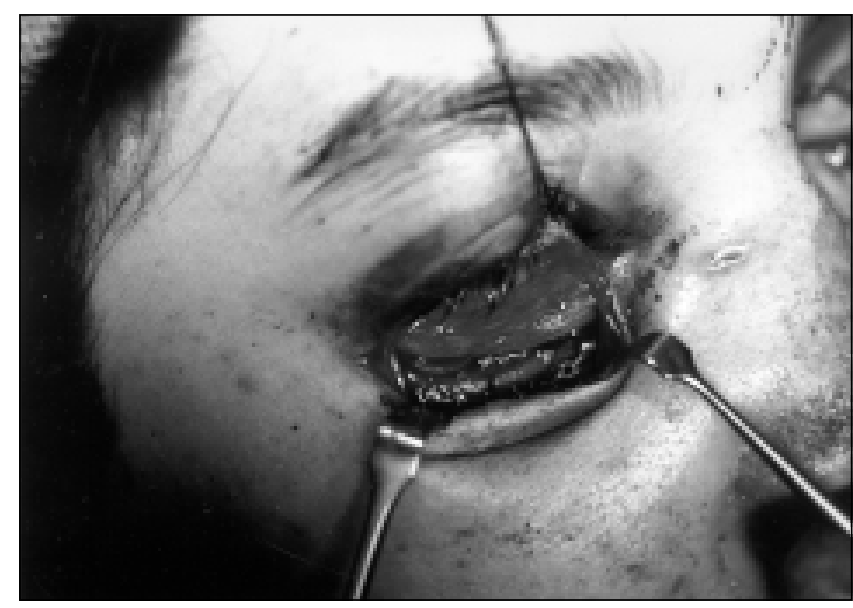

Figure 3) Open reduction and internal fixation via a subciliary approach to the orbit

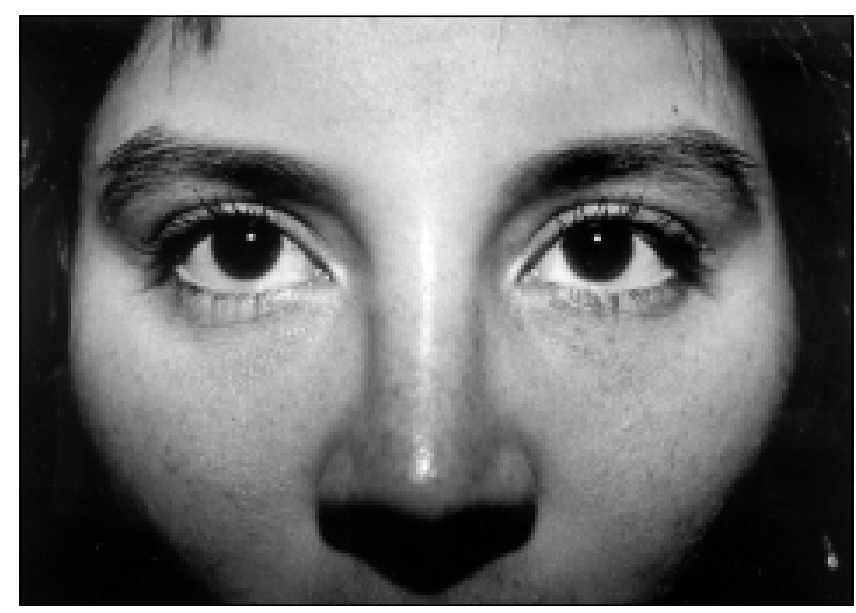

Figure 4) Satisfactory functional and aesthetic result one month after operation

subtle medial orbital and other bony fractures beyond the obvious nasal injury. This review aims to underscore the importance of those clinical findings present on the initial examination suggestive of this type of injury and most likely to benefit from radiological investigation and contemporary techniques of exposure, reduction and rigid fixation.

\section{Case 1}

\section{CASE PRESENTATIONS}

A 27-year-old woman was injured with a softball (Figure 1). The impact of the softball was on the lateral nasal wall and infraorbital rim. She was examined by the treating physician, who planned closed nasal reduction without any further workup, despite the presence of asymmetric periorbital edema and ecchymosis, subconjunctival hematoma, stepdeformity along the infraorbital rim, dysesthesia of the infraorbital nerve, nasal bridge deviation and blunting of the medial canthus. A second physician, however, ordered a facial computed tomography (CT) scan, which revealed fractures of both the medial wall and infraorbital rim with an accompanying orbital floor defect (Figure 2). Operative exposure via a subciliary approach revealed that the lower 


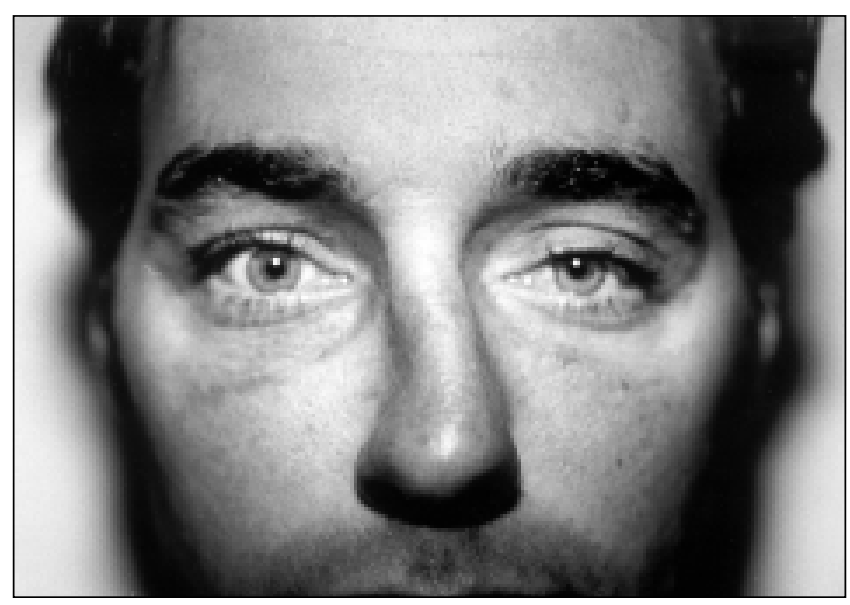

Figure 5) Lateral impact injury with nasal bridge deviation, midfacial dysesthesia, step deformity of the infraorbital rim and subcutaneous emphysema

two-thirds of the medial orbit was fractured at the pyriform and the inferior orbital rim (Figure 3). The nasal bones and orbital floor were also found to be fractured, with maintenance of the attachment of the ascending process of the maxilla to the frontal bone. Open reduction and internal fixation with split cranial bone grafting provided satisfactory functional and aesthetic postoperative results (Figure 4).

\section{Case 2}

A 24-year-old male college student was involved in a physical altercation and was punched on the lateral aspect of the nose (Figure 5). He was diagnosed with a unilateral depressed nasal fracture by the treating physician. On physical examination, however, he had evidence of blunting of the medial canthus, deviation of the nasal bridge, midfacial dysesthesia, mild step deformity along the infraorbital rim and subcutaneous emphysema - all suggestive of a more complex injury. A CT scan showed fractures in the medial orbital wall and orbital floor, injuries that clearly would not have been addressed if he were treated for a nasal fracture alone (Figure 6). The patient underwent operative intervention with transconjunctival and gingivobuccal sulcus approaches, with rigid fixation of the orbital rim and split cranial bone grafting to the orbital floor.

\section{Case 3}

A 45-year-old man was struck on the left side of his nose with a pole while at work. He was evaluated in the emergency room and sent home after specialist evaluation, with a diagnosis of a possible nasal fracture not requiring any acute treatment. He was followed as an outpatient by his family physician, who referred the patient to the plastic surgery service for evaluation of persistent epiphora two weeks after his injury. Physical examination revealed dysesthesia in the distribution of the infraorbital nerve and a subtle step deformity of the infraorbital rim and frontal process of the maxilla. A CT scan localized fractures to the medial orbital wall and frontal process of the maxilla. He underwent successful

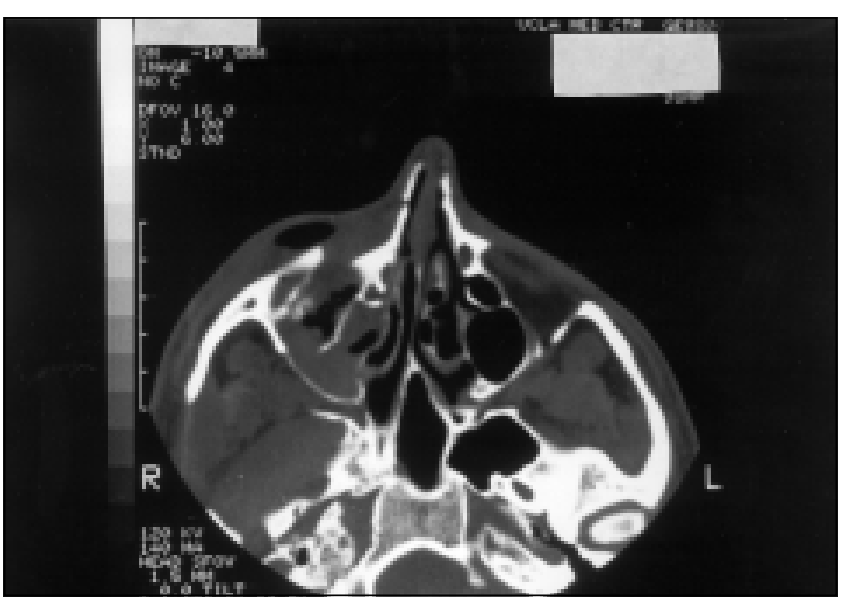

Figure 6) Coronal computed tomographic image depicting medial orbital wall and orbital floor fractures

open reduction and internal fixation from a subciliary approach, achieving good postoperative results.

\section{DISCUSSION}

The successful diagnosis and treatment of complex nasal fractures is predicated on a detailed appreciation of the regional midfacial anatomy $(15,16)$. The nasal septum comprises the vomer bone inferiorly, the perpendicular plate of the ethmoid posteriorly and the quadrangular cartilage anteriorly. The septum is lined with a vascular mucoperiosteal and mucoperichondrial envelope, which is easily torn and prone to hematoma formation during fracture dislocation. The bony structure of the nasal pyramid consists of the nasal bones, supported laterally by the structurally stronger frontal process of the maxilla (17). Their superior articulation with the nasofrontal junction and the internal angular process of the frontal bone, combine to create the main structural buttress of the naso-orbital ethmoid region $(9,18)$. The lateral border of the vertical buttress comprises the medial orbital wall where the medial canthus inserts. It consists of the frontal process of the maxilla and lacrimal bone anteriorly with the lamina papyracea of the ethmoid bone posteriorly (19-21). This region often buckles in response to external forces in continuity with the most vulnerable segment of the orbital floor, immediately posterior and medial to the infraorbital groove $(19,22)$.

The confluence of these distinct osseous components, together with their soft tissue coverings, combine to create the NOE complex, which has been acknowledged as the most challenging of all craniofacial areas to reconstruct $(20,23,24)$. The most precise definition of a fracture within this region involves separation of the lower two-thirds of the medial orbital rim along with the medial canthus from adjacent bones $(9,18)$. Synchronous fractures of the lateral nasal bones, the medial orbital wall, the infraorbital rim and floor, the pyriform aperture and the superior articulation of the frontal process of the maxilla are prerequisites for a true NOE fracture (10). In less severe instances of facial trauma, the 
NOE fracture may not be entirely displaced; rather, a single articulation (usually superior) may be 'greensticked', with displacement of the remaining articulations. Invariably, these subtle or occult findings escape detection in the context of a nasal fracture. This tends to obscure the clinical evaluation of the all important NOE.

The literature is replete with classification systems for nasal and NOE fractures $(4,9,17,18)$. Stranc and Robertson (4) are generally credited with the most practical approach to nasal fractures, characterizing lateral and posterior displacements independently. Lateral impact forces are more common and are usually associated with unilateral bony depressions that are readily amenable to closed reduction. Significant lateral injuries, however, can cause outward displacements of the contralateral nasal bones and/or a cantilevering effect on the ipsilateral ascending process of the maxilla at its cephalic articulation. These injuries appear to be disproportionately implicated in occult NOE injuries as our cases have highlighted. Indeed, in a series of loading experiments, more significant damage to the nasal bones and adjacent bony structures was encountered with lateral than with frontal impacts of similar force (17).

Frontal impact nasal injuries are divided into categories based on the degree of comminution and posterior displacement. Plane I and II injuries are confined to the nasal osseocartilaginous superstructure, whereas plane III injuries demonstrate fractures that extend beyond. The plane III category details combined fractures of the nasal skeleton, maxilla, pyriform aperture, frontal, ethmoid and orbital bones, which is synonymous with an NOE fracture $(4,10)$.

Injuries of the NOE complex are defined as unilateral or bilateral and are either isolated to the central midface or extended to adjacent anatomical areas. The state of the medial orbital rim or central fragment of an NOE fracture is the basis for the most comprehensive classification of fractures in this area (9). The type I injury is characterized by the central fragment existing as a single nondisplaced or displaced segment at the internal angular process of the frontal bone. Comminution in the central fragment remains external to the insertion of the medial canthal tendon in the type II injury, while fracture of the central fragment, including the region of the canthal insertion, is classified as a type III NOE injury.

The clinical recognition and treatment of NOE fractures has been succinctly described by a number of authors; however, in the absence of severe midfacial trauma, diagnosing subtle fractures and minimal displacement within the NOE becomes a formidable task $(5,9,25)$. Edema, periorbital ecchymosis and epistaxis are ubiquitous with injuries in this area. Similarly, the unequivocal findings of telecanthus, orbital dystopias, nasal bridge and nasofrontal angle defects, cerebrospinal fluid leaks and the spectacle hematoma (hematoma extending to the insertion of the orbital septum) are highly suspect, if not pathognomonic, for NOE fracture $(9,15)$. However, concurrent step deformities along the infraorbital rim, subconjunctival hemorrhage, hyphema, subcutaneous emphysema, pseudotelecanthus, epiphora and blunting of the medial canthus are equivocal clinical findings that mandate further investigation to rule out occult injuries of the NOE complex. Practically speaking, the clinical findings associated with injury to this area represent gradations of severity that obviate the need to look beyond nasal and NOE fractures as independent clinical entities. The reconstructive surgeon must be cognizant of this continuum and maintain a low threshold for ordering imaging studies. The detection of occult fractures is crucial to expediting appropriate intervention. Concurrent nasal and NOE fracture reduction at the initial setting avoids the aesthetic and functional morbidity associated with unrecognized fractures to this area and the challenges of secondary surgical revision (18).

Physical examination of this region has yielded less information than that for suspected fractures elsewhere in the facial skeleton. Furnas and Bircoll (26) popularized the eyelash traction test to assess the integrity of the medial canthal ligamentous attachment, while others have popularized bimanual examination (11). Neither technique has supplanted the use of imaging technology, which has assumed an increasingly dominant role in both diagnostic and therapeutic aspects of patient management.

CT has made an enormous impact in craniofacial trauma. Technical innovations in CT imaging have produced high resolution, multisectional images amenable to further refinements of magnification and three-dimensional reconstruction. The ability to depict accurately the bony and soft tissue anatomy in axial and coronal planes is a major advance in delineating precise fracture patterns. In conjunction with the physical examination, CT has also afforded the plastic surgeon guidelines for complex facial fracture management and classifications of injury $(9,18)$.

Simple depressed nasal fractures are sufficiently managed with elevation and septal reduction, while more severe injuries are managed by formal reduction after the completion of residual fractures. Highly segmented but isolated nasal injuries (frontal plane II) are best managed by the application of external bolsters to stabilize nasal width and height or an open reduction with the possibility of bone grafting.

Optimal treatment of fractures requires early exploration and open reduction combined with interfragmentary wiring and plate fixation consistent with the severity of injury $(5,9,27)$. Exposure is attained with coronal, subciliary or transconjunctival approaches; however, pre-existing lacerations supplemented with maxillary gingivobuccal sulcus incisions allow access to the entire region.

In unilateral minimally displaced fractures of the NOE area, reduction and internal fixation at the affected buttresses suffice in restoring structural integrity. Inferior exposure alone with stabilization of the infraorbital rim and/or the nasomaxillary buttress is usually all that is necessary. Bilateral single fragment injuries usually require stabilization by midfacial adaptation plates superiorly and by rigid plate fixation inferiorly. Comminuted unilateral or bilateral injuries require isolation and mobilization of the central fragment. The canthal ligamentous attachment is preserved at its bony insertion followed by interfragment wiring and transnasal reduction of the medial orbit, canthal-bearing bone fragment. Rigid fixa- 
tion is subsequently applied both superiorly and inferiorly to complete the procedure. Injuries in which comminution extends through the medial canthal insertion are fortunately less common (9). Canthal stripping, transnasal canthopexy and bone grafting are the keys to management, in addition to the previously described approaches, to realign precisely the medial orbital margin.

Reconstruction of the internal medial orbit and floor is frequently required in comminuted fractures (28). Calvarial bone grafts are often used, supplemented, on occasion, with metal orbital plates or mesh for bone graft support. Normal orbital volume and shape must be restored to avoid enophthalmos and ocular dystopia $(9,15)$. Primary bone grafting for cantilever reconstruction of the nasal skeleton is also sometimes required to restore premorbid projection and continuity.

\section{CONCLUSIONS}

Complex nasal injuries with subtle fracture extensions to the NOE complex are often missed by the treating surgeon. These minimal or occult injuries benefit from a high index of suspicion, particularly in patients with lateral impact and equivocal clinical findings. Axial and coronal CT images with bone and soft tissue windows provide precise diagnostic information in these difficult cases. Surgical exposure via coronal, subciliary, transconjunctival and maxillary gingivobuccal sulcus incisions or pre-existing local lacerations allows complete fracture visualization. Interfragment and transnasal wiring, if required, in conjunction with contemporary rigid fixation with bone grafting of osseous defects constitutes appropriate management.

\section{REFERENCES}

1. Greene D, Raven R, Carvalho G, Maas CS. Epidemiology of facial injury in blunt assault. Determinants of incidence and outcome in 802 patients. Arch Otolaryngol Head Neck Surg 1997;123:923-8.

2. Schroeder HG, Eichhorn T, Glanz H, Kleinsasser O. [Classification of the isolated fractures of the nasal pyramid]. HNO 1981;29:335-8.

3. Stranc MF. Primary treatment of naso-ethmoid injuries with increased intercanthal distance. Br J Plast Surg 1970;23:8-25.

4. Stranc MF, Robertson GA. A classification of injuries of the nasal skeleton. Ann Plast Surg 1979;2:468-74.

5. Gruss JS. Naso-ethmoid-orbital fractures: classification and role of primary bone grafting. Plast Reconstr Surg 1985;75:303-17.

6. Pollock RA. Nasal trauma: pathomechanics and surgical management of acute injuries. Clin Plast Surg 1992;19:133-47.
7. Courtiss EH. Septorhinoplasty of the traumatically deformed nose. Ann Plast Surg 1978;1:443-9.

8. Leipziger LS, Manson PN. Nasoethmoid orbital fractures. Current concepts and management principles. Clin Plast Surg 1992;19:167-93.

9. Markowitz BL, Manson PN, Sargent L, et al. Management of the medial canthal tendon in nasoethmoid orbital fractures: the importance of the central fragment in classification and treatment. Plast Reconstr Surg 1991:87:843-53.

10. Evans GRD, Clark N, Manson PN. Identification and management of minimally displaced nasoethmoidal orbital fractures. Ann Plast Surg 1995;35:469-73.

11. Paskert JP, Manson PN. The bimanual examination for assessing instability in naso-orbitoethmoidal injuries. Plast Reconstr Surg 1989;83:165-7.

12. Converse JM, Smith B. Naso-orbital fractures and traumatic deformities of the medial canthus. Plast Reconstr Surg 1966;38:147-62.

13. Manson PN, Crawley WA, Yaremchuk MJ, Rochman GM, Hoopes JG, French JH Jr. Midface fractures: advantages of immediate extended open reduction and bone grafting. Plast Reconstr Surg 1985;76:1-12.

14. Markowitz BL, Manson PN. Panfacial fractures: organization of treatment. Clin Plast Surg 1989;16:105-14.

15. Jackson IT. Classification and treatment of orbitozygomatic and orbitoethmoid fractures. The place of bone grafting and plastic fixation. Clin Plast Surg 1989;16:77-91.

16. Clark GM, Wallace CS. Analysis of nasal support. Arch Otolaryngol 1970;92:118-23.

18. Manson PN, Markowitz BL, Mirvis S, Shockley WW. Toward CT-based facial fracture treatment. Plast Reconstr Surg 1990;85:202-12.

19. McQueen CT, DiRuggiero DC, Campbell JP, Shockley WW. Orbital osteology: a study of the surgical landmarks. Laryngoscope 1995; 105:783-8.

20. Antonyshyn O, Gruss JS. Complex orbital trauma: the role of rigid fixation and primary bone grafting. Adv Ophthalmic Plast Reconstr Surg 1988;7:61.

21. Manson PN, Hoopes JE, Su CT. Structural pillars of the facial skeleton. Plast Reconstr Surg 1980;66:54-62.

22. Manson PN. Facial bone healing and grafts. A review of clinical physiology. Clin Plast Surg 1994;21:331-48.

23. Whitaker LA, Yaremchuk MJ. Secondary reconstruction of posttraumatic orbital deformities. Ann Plast Surg 1990;25:440-9.

24. Zide BM, McCarthy JG. The medial canthus revisited - an anatomical basis for canthopexy. Ann Plast Surg 1983;11:1-9.

25. Gruss JS, Phillips JH. Complex facial trauma: the evolving role of rigid fixation and immediate bone graft reconstruction. Clin Plast Surg 1989;16:93-104.

26. Furnas DW, Bircoll MJ. Eyelash traction test to determine if the medial canthal ligament is detached. Plast Reconstr Surg 1973;52:315-7.

27. Gruss JS, Mackinnon SE. Complex maxillary fractures: role of buttress reconstruction and immediate bone grafts. Plast Reconstr Surg 1986;78:9-22.

28. Kawamoto HK Jr. Late posttraumatic enophthalmos: a correctable deformity? Plast Reconstr Surg 1982;69:423-32. 